\title{
International Cooperation to Prevent and Combat Transnational Drug Trafficking at Border Locations: A Case Study of Vietnam
}

\author{
Tran Quang Huyen \\ Vice-Rector of the People's Police College I \\ Thanh Xuan District, Hanoi, Vietnam 100000
}

\begin{abstract}
Vietnam has recorded as one of the new areas in the transnational flows of illicit at Southeast Asia. Locating at the close outbound of the Golden Triangle - the second hub of opium cultivation around the world, Vietnam has been impacting, directly or indirectly, on drug production, consumption, and trafficking in recent years. Meanwhile, at the current moment, in Vietnam, the situation of a drug crime has been experiencing complicated happenings with increasingly sophisticated, artful nature and artifice. This paper provides the overall background of Vietnam via clarifying a geographical feature to impact on borderlines on land and sea about the Southeast Asia region. Besides, the study analyses the picture of the current situation of drug trafficking in Vietnam, particularly focusing on trends and patterns of drug-related crimes in the borderland and on the sea routes among Vietnam and other shared borders, including China, Cambodia, and Laos. Main reasons to explain why Vietnam has been becoming as a transnational hub in the region that also assess carefully in the next section before demonstrating the role of Vietnam's authorities to cooperate and collaborate with other nations to combat transnational drug trafficking. Some recommendations and proposals to improve the effectiveness of international cooperation to fight drugrelated crimes are also called for further researches.
\end{abstract}

Keywords: Drug trafficking; Borderland; Transnational Crimes; ASEAN; Anti-Narcotics Crime Investigation Police Department (ANCIPD); International Cooperation; Law Enforcement Agencies (LEAs); Vietnam

DOI: $10.7176 / \mathrm{JLPG} / 85-24$

Publication date:May $31^{\text {st }} 2019$

\section{Introduction}

The world is facing the emergence and increase of new psychotropic substances. The Golden Triangle region encompasses many ASEAN member countries and continues to be the hot spot of poppy cultivation and is emerging as the world's center for synthetic drug production. According to UNODC (2019), the East and Southeast Asia now have more than 3 million heroin users and more than 5 million artificial drug users, mostly amphetaminetype-stimulants (ATS), and indeed, the world is facing the emergence and increase of new psychotropic substances (NPS). More and more new chemicals and precursors are not included in the list of controlled international conventions used to synthesize synthetic drugs, and even, darknet and drug markets on the internet are growing (Ladegaard, 2019; Moyle, Childs, Coomber, \& Barratt, 2019; Tasch, 2015). Besides, criminal organizations have taken advantage of the development of science and technology to commit crimes with nature, the more sophisticated and cunning days and even, they enticed, bribed chemical experts to study and invent new types of drugs. More and more new chemicals and precursors are not included in the list of controlled international conventions used by synthetic drug modifiers (ASEAN-NARCO, 2018; UNODC, 2018). Black websites, drug markets on the internet are growing, with drug transactions, buying and selling with encrypted messages over the internet and paying by electronic money like Bitcoin replacing cash (Ladegaard, 2019; Tasch, 2015). Also, several countries around the world are showing a tendency to legalize drug use (cannabis) such as Canada, Thailand, and Paraguay (IDPC, 2018, 2019). These are significant challenges, posing requirements and everyday tasks for drug prevention and fight forces of countries in the region need more enhanced and supportive cooperation (ASEANNARCO, 2018; UNODC, 2018).

\section{Geographical Features}

Vietnam is a country located in the strategic geographic position in the Southeast Asian area. This geographical position has defined some essential characteristics of nature as well as creating a diverse and vibrant differentiation of natural resources. In terms of economy-politics-society, this position both facilitates and makes it difficult for Vietnam to exchange, approach and development among countries in Southeast Asia (Hiep, 2014; Thayer, 2011). In the context of regional integration, Vietnam's geographical position has brought many opportunities and many challenges for its national development and participation in regional integration.

In terms of natural geography, Vietnam is located on the eastern edge, stretching throughout the East flank and the southern flank of the Indochinese peninsula; occupies the majority of the peninsula and is at the center of Southeast Asia (Hai, 2017; Hiep, 2014, 2017). Vietnam has just been associated with the Eurasian continent and is adjacent to the South China Sea and the Pacific Ocean. Vietnam consists of two territorial parts on the mainland and the sea, the continental shelf under the sovereignty and jurisdiction of the nation. Some scholars have pointed 
out that Vietnam's geographical position has five characteristics that these characteristics dominate all benefits and challenges to Vietnam's position formation, follow as (Hiep, 2017; Thayer, 2010 2012; Turner, Bonnin, \& Michaud, 2015; Vuving, 2010; Wilson, 2018):

- Vietnam lies entirely in Southeast Asia's tropical monsoon tropical belt;

- Vietnam is located in the Western Pacific and Mediterranean ecosystems, located in the area affected by volcanic and earthquake arcs, which is also the transitional place of the biological world with many different zones;

- Vietnam has a mainland part of the eastern Central Indian peninsula, in the southeast corner of the Eurasian continent; the sea consists of two archipelagos, Parcel and Spratly Islands (Hoang Sa and Truong Sa in Vietnamese language), located in the center of the East Sea, connecting the Pacific Ocean with the Indian Ocean;

- Vietnam is close to China, is a vast country, is developing a strong economy and has a long-standing cultural historical relationship;

- Vietnam is located in the center of Southeast Asia, at the same time in the regional center of dynamic and emerging developed countries, including East Asia, South Asia, and Australia.

Naturally, Vietnam is a country with a diverse diversity of nature, differentiating between North and South as well as East and West. However, there are also some common characteristics that express the unity of the natural geographical environment. With its position among many physical systems, Vietnam has rich and diverse biological resources from tropical, subtropical and temperate organisms. As a country bordering the sea, Vietnam is deeply influenced by the sea. At the same time in the contiguous position between the continent and the ocean, Vietnam is both continental and maritime. Accordingly, Vietnam is a country with a long border line along the mainland and on the sea. It creates a border area with dedicated management regulations to protect borderline and national sovereignty. Under the current legislation of Vietnam, all border areas regulated by Law on National Border Law and refers on land border areas including communes, wards, towns which have a part of borderline coinciding with the on land national borders; border areas on the sea are defined from national border area on the sea to administrative border line at communes, wards and towns which are nearby seas and islands.

\subsection{Borderline on the Land}

In terms of borderland scope, generally, Vietnam is divided into three main routes. Firstly, Vietnam - Lao border is 2,067 km of length and crossing ten provinces such as Dien Bien, Son La, Thanh Hoa, Nghe An, Ha Tinh, Quang Binh, Quang Tri, Thua Thien- Hue, Quang Nam and a part of Kon Tum. The whole route has 35 districts, 139 communes, one town; there are 52 border gates in which there are seven international border gate, six primary border gates and 39 secondary border gates. Secondly, Vietnam - China border is 1,463 km of length and crossing six provinces such as Quang Ninh, Cao Bang, Ha Giang, Lang Son, Lao Cai, and Lai Chau. The whole route has 30 districts, two towns, 150 communes, three townships, six wards, 40 border gates, in which there are five international border gates, three primary border gates, and 42 secondary border gates. Thirdly, Vietnam Cambodia border is 1,137 km of length and crossing 9 provinces, including Gia Lai, Dak Lak, Dak Nong, Tay Ninh, Binh Phuoc, Long An, Dong Thap, An Giang, Kien Giang and one part of Kon Tum, in which Ngoc Hoi District is nearby two countries such as Lao and Cambodia at the Bo Y International Border Gate. The whole route has 30 districts, 100 towns, one ward, 47 border gates, in which there are nine international border gates, seven primary border gates, and 31 secondary border gates.

\subsection{Borderline on the Sea}

Regarding borderlines on the sea, Vietnam has the coast of 3,260 km of length straightening from the North to the South and stand on the $27^{\text {th }}$ rank of 157 coastal countries, islands and territories over the world. As prescribed by the United Nations Convention on Law of the Sea 1982 (starting now as Convention on Law of the Sea 1982), Vietnam has sea area of over one million $\mathrm{km}$, more significant than three times the land area and occupied nearly $30 \%$ the area of the East Sea. Vietnam sea territories have about 3,000 large and small islands and two offshore islands, namely Parcel (Hoang $\mathrm{Sa}$ and Truong $\mathrm{Sa}$ in the Vietnamese language). The Vietnam sea borderline is contiguous to 6 countries including China, Thailand, Malaysia, Cambodia, Indonesia, and the Philippines. Coastal length is 3,260 km crossing 28 provinces and cities including 136 districts in which there are 675 communes, wards, towns belongings to on the sea frontiers area. In particular, there are 44 big and small seaports. Total length is about $24,000 \mathrm{~m}$ of piers with the volume of cargoes loaded about 100 million tons per year, accounting for over $80 \%$ of imported and exported shipments of the country.

\section{Drug Trafficking in Vietnam: Trends and Patterns}

The operation of drug-related crimes, particularly with transnational drug trafficking between Vietnam and other countries, is complicated. From $16^{\text {th }}$ November, 2017 to $15^{\text {th }}$ August, 2018, the Anti-Narcotics Crimes Investigation Police Department (ANCIPD) of Ministry of Public Security (MPS) coordinated with functional forces to investigated 24,552 cases and arrested 37,842 subjects, seized 1,584.36 kg of heroin, $136.98 \mathrm{~kg}$ of cocaine, $196.65 \mathrm{~kg}$ of opium, 254.4 kilograms of marijuana, 4.2 kilograms of U.S. grass, $6.23 \mathrm{~kg}$ of ketamine, $1,755.74 \mathrm{~kg}$ 
and 1,363,405 synthetic drug tables and also collected 133 guns and 2,044 bullets as well as seized VND 82 billions (around US\$ 40 millions) (MPS, 2018). Regarding the situation at borderlines between Vietnam and shared border's countries, in 2018, all LEAs of Vietnam investigated and arrested 1,071 cases, 1,396 drug offenders; seized 1,240 kg of drugs of all kinds. Of which, 123 kilograms of heroin; 705 kilograms of synthetic drugs; 35 kilograms of opium resin; $1 \mathrm{~kg}$ Cocaine; 376 kilograms of marijuana; 30 guns of all kinds; 299 rounds and many other exhibits (MPS, 2018). From the beginning of 2019 until now, many drug transport cases have been seized. In particular, only in the first three months of 2019, more than 6 tons of drugs, almost ATS, and heroin were seized which was more significant than the whole of 2018 and much than nearly three times in 2017. Cases from early 2019 to now include almost $300 \mathrm{~kg}$ of drugs were seized at Cau Treo International Border Gate (Ha Tinh province) in February and then 570 kilograms of rock drug caught in Ho Chi Minh City (HCMC) in March. After that, during one week of April, the ANCIPD headquartered and provincial levels destroyed 3 significant cases, seized $700 \mathrm{~kg}$ of stone drugs in Quynh Luu district 600 kilograms of stone drugs in Vinh City (Nghe An province) and 1.1 tons of stone drugs in HCMC and these cases have organized and monitored by Chinese and Taiwanese drug lord collude to Vietnamese subordinators (Hai, 2019b; Thang, 2019).

Vietnam is recorded as a transportation hub in the region. According to the ANCIPD, synthetic drugs from the Golden Triangle area, a rugged mountain forest located between the borders of Laos, Thailand, and Myanmar, are spreading all over the world. Vietnam lies on this flow (Hai, 2019b; MPS, 2018). Traffickers took several advantages of geographies, typographies, and climate conditions to transport and trade illicit drugs into and/or through Vietnam and beyond (Hai, 2019a, 2019b). Methods and tricks of drug offenders are very sophisticated, cunning and more and more dynamic. The leading subjects often rarely reveal their identity but often direct their accomplices to source goods, provide financial support and hire transport objects. Based on the available relations between peoples, relatives and kin in the family to transport drugs across the border into Vietnam then hook up with other people to take medicines to consume in provinces or shipping to third countries and even, margins join lines or inventories to get them to work.

\subsection{On the Borderland Routes}

In Vietnam, transnational drug trafficking happens extensively throughout crossing border gates, mostly located in provinces of North-West, North in the Central Area and South -West. There are various drugs and substances traded illegally across these hot spots, including heroin, ATS, and NPS. In which, heroin and synthetic drugs are most frequently and increasingly traded, and transport; narcotics and marijuana tend to decrease in trading and to transport. Cross-border and land border gate drug traffickers are very diverse including foreigners and Vietnamese, professional and non-professional persons. Accordingly, for example, between the Vietnam-Laos border, traffickers often change their operating areas, divert drug transport to Central Lao provinces to enter Vietnam when any primary drug transport routes have been prevented. Meanwhile, crossing Vietnam-Cambodia border all kinds of heroin, Ketamine, Mefomketamin produced and processed from the Golden Triangle area will be transferred into Cambodia via Natanatakiri province along the border, then re-packing, branding, and shipping to other countries, including Vietnam (ASEAN-NARCO, 2018; MPS, 2018).

Mainly, crossing the Northern routes between Vietnam and Laos and China, there are many hotspots of drug trafficking. In six provinces in the North West, there are still some complicated areas of drug-related crimes such as Mai Chau - Hoa Binh; Van Ho, Moc Chau and Song Ma districts - Son La; Dien Bien Dong and Dien Bien districts - Dien Bien province; Lao Cai City, Muong Khuong District - Lao Cai (VNS, 2018; VTV, 2018). In these hot spots, drug offenders are very active and aggressive to protest LEAs. More dangerous is that drug criminals seek to exploit, entice, bribe some degenerate and degenerate officials in communes and villages such as Ta De, Lung Xa, Co Tang, Loong Luong commune, border areas. According to customs and practices and to protect goods (drugs), most of the subjects often store and illegally use weapons, support tools, and actively resist the functional forces when being arrested. hold, cause difficulties and challenges for operational authorities (VNS, 2018; VTV, 2018).

\subsection{On the Sea Routes}

Apart from land border gates, drug trafficking is very sophisticated, both single and organizational transportation, passing the border gate and border paths, drugs hidden in cargoes, hand language, and the human body. Sea routes are mainly on the Balkan Line (across the Islamic Republic of Iran and Turkey then crossing South-East Europe to West and Central Europe); Northern Line (crossing Central Asia to the Russian Federation) and Southern Line (Gulf, South Asia, and Africa). The Balkan Line accounts for nearly half of the heroin and coin which are seized around the world and continues to be the most critical opiate drug trafficking route in the world. According to internationally aggregated data, there are about 420 million containers every year shipped worldwide by sea. Meanwhile, less than $2 \%$ of such activities are controlled. This poses a significant risk to transnational crimes taking advantage of this method to transport drugs and other illegal substances.

Vietnam is a country in the west of the East Sea, with a long coastline from the Gulf of Tonkin to the Gulf of 
Thailand. This is a critical bridge that will facilitate Vietnam's socio-economic development, but this is also a favorable condition for drug criminals to operate powerfully, including the illegal trading and transportation of narcotics by the sea. Currently, Vietnam is at risk of both drug transshipment areas and drug consuming areas with about $80 \%$ of drugs shipped into Vietnam shipped to third countries (MPS, 2018). Drug crime activities are taking place very complicated in the southern provinces, including HCMC, with the number of drugs arrested and growing. Cat Lai Port (HCMC) is the biggest cargo port in the country, averaging 2,000 - 3,000 containers per day at here, goods are divided into green, yellow and red channels in which classify these lines based on priority when carrying out procedures. The drug-containing shipment shipped to the Philippines just belonged to the yellow stream, only checking the file. In April 2019, the ANCIPD of Vietnam has arrested Taiwanese drug lord and his syndicate and also arrested $400 \mathrm{~kg}$ of drugs, suspected of transporting from Cat Lai port, in which drugs were mixed with other items and packed in cargo containers to be taken away. Many drug companies and lines conceal their behavior by borrowing an import-export company to act as a frontier for drug trafficking. Therefore, the new situation requires border guards, police and customs to coordinate with each other to monitor and detect as soon as drugs are brought into Vietnam, through roads and seaports. In particular, it is necessary to strengthen the role of customs forces at ports.

\subsection{Vietnam: As a Transnational Hub}

There are main reasons why the border areas, from North to South as well as Central Northern region that have been becoming as one of the critical routes of drug-related crime in and through Vietnam.

Firstly, Vietnam is contiguous, so it is directly affected by the "Golden Triangle" area - a primary drug production and trading center in the world. Border control and management across the border areas, both the land and the sea, is complicated due to the long border line, mainly the rugged mountainous terrain with many border gates and trails, unqualified roads as well as long coastal with several seaports in the whole of the country.

Secondly, in the past years, although the Party and State have applied many policies to support socioeconomic development, the lives of ethnic minority people in the almost mountainous provinces in Vietnam, especially in remote areas far away, the border area is still facing many difficulties, the intellectual level is still limited. People on both sides of the border (notably the Hmong) often have close ties, often crossing with each other, so they are more likely to be attracted, bribed and involved in drug transport.

Thirdly, although almost provinces shared borderland with Cambodia, China and Laos are mountainous provinces, the transportation network is connected to the lowland provinces very smoothly. Also, there are several river routes with favorable conditions, drug offenders who buy drugs and then transport them to lowland provinces to consume in different ways. Therefore, in spite of being aware of the strict criminal policy of the law on drugrelated crimes, many people for the super-profit still disobey the law and seek ways to involve drug trafficking.

Fourthly, the force of drug prevention and fight in the mountainous provinces has been strengthened but it still lacks in quantity, and weak in terms of professional skills and technical facilities for combat are limited, especially in the border areas. Prevention campaigns, including occupational prevention and social prevention, have not been conducted regularly and continuously. Also, the coordination between forces such as Police, Border Guard and Customs in the fight against drug-related crime in the border area has not been improved consistently and continuously. At all levels and sectors, the competition is not fierce, and the efficiency is not high.

Fifthly, committee level, authorities in some localities, especially in remote, isolated and border areas are weak, and many core officials are subject to the binding customs and habits, the family should not be brave in the direction and coordination in the implementation of the struggle against drug-related crimes. The campaign and propaganda for ethnic minority people to improve the sense of law observance and the spirit of fighting against crimes have not been frequent. Besides that, the situation of planting and re-planting plants containing narcotics is still complicated. To avoid the detection of the authorities, the subjects sought to plant opium in remote, border and border areas, even cross the border to the land of Laos to grow. Although the field of re-planting opium was discovered and arrested, this is not an alarming issue. If there is no solution, there will be a risk of reemergence. For example, in 2014, functional forces discovered and destroyed some areas of re-growing opium plants such as Son La province 2.59 ha; Dien Bien province 3,854 ha; Lai Chau province 11.36 ha (MPS, 2017).

Sixthly, crossing the remoted areas shared borders with Cambodia, China and Laos, the situation of illegally storing and using military weapons, self-made weapons and explosives is very complicated. The authorities have repeatedly lobbied and called for the submission of weapons, but many subjects still did not give up. Many wanted people to seek to hide in border areas, armed and continue to connect to form transnational drug transport lines. Meanwhile, the Lao people, Chinese people also took advantage of friendly relations with Vietnam, frequently traveling across the border area to fabricate tourism, visiting relatives or trading to purchase activities for the purpose of trading illegal narcotics.

Seventhly, the cooperation relationship in the fight against drug crime between Vietnamese authorities and the authorities of Cambodia, China and Laos has been expanded, but the effectiveness has been limited to share information and joint investigation. The exchange of information and coordination of investigation and arrest of 
drug-related crimes in each country has not yet met the requirements of struggle practice, and information exchange has not been frequent and timely.

\section{Vietnam's Responses in International Cooperation to Combat Drug Trafficking}

The Government of Vietnam recognizes excellent importance to international cooperation in drug prevention and control, by strengthening and expanding bilateral and multilateral cooperation in drug prevention and combat with other countries, particularly with shared border's lands in the region. The competent authorities of Vietnam are responsible for implementing cooperation programs on drug prevention and combat with relevant agencies of countries, international organizations, foreign organizations, and individuals. The State of Vietnam clearly shows its viewpoint: Prioritizing the country to sign bilateral international agreements with Vietnam with legal assistance in the investigation, prosecution and trial of drug-related crimes, particularly with three main shared border's nations, including China, Cambodia, and Laos.

Since 2012, the mechanism of the ASEAN Ministerial Meeting on drug issues has been established and officially institutionalized since 2015, bringing drug prevention and cooperation among ASEAN countries to a new level for demonstrating ASEAN's strong commitment to solving drug problems (ASEAN-NARCO, 2017, 2018). To promptly respond to the current drug situation, strengthening the efficiency and quality of the agenda of the senior and ministerial level meetings based on multilateral and bilateral cooperation' mechanism that should be prioritized.

At the same time, with the initiatives and cooperation mechanisms already in place, it is necessary to step up the activities into the nature and diversity of contents and forms of implementation, creating cohesion and promoting the strengths of each country as well as the overall strength of ASEAN countries. For Vietnam, in recent years, all LEAs, including ANCIPD in combination with the functional forces of Border Guards, Customs, and Maritime Police Forces (Military) have paid attention to directing and determining the coordination with their partners in regional area, especially those bordering the on-land and on sea borderlines such as Laos, China, Cambodia, Thailand, Malaysia, Indonesia, and the Philippines. Based on ASEAN Transnational Crimes Agreements and its related documents to prevent and combat transnational drug trafficking, among LEAs to conduct exchanges, handing over and making briefings on activities of prevention and fight against drug crimes in the region. Meetings were organized to exchange information on the situation of drug-related crimes, to announce new modes and tactics for new activities; the situation of purchasing, transporting, exporting and importing addictive drugs, psychotropic drug and illegal precursor crossing borderlines on land and sea; to exchange experiences in prevention and detection of drug-related crimes, experiences in organizing forces, coordinating in training and training officials enforcing the law on drug prevention and fight and in exchanging legal documents on drug control; to exchange the coordination in arrest, extradition and investigation of drug crimes.

\subsection{Response on the Borderland}

To support regional countries, the UNODC has called on the international community to support the regional project - "Strengthening and enhancing the regime of Border Liaison Offices (BLO) in the East Asian region "(RAS / I61) 2005-2010 within the framework of the Drug Control Memorandum. It contributed to make plan for sub-regional actions with the aim of building the power for the BLOs, strengthening the coordination of functional forces located in border areas between countries in the region (UNODC, 2013, 2017). From 1999 to 2011, with the help of the United Nations Office on Drugs and Crime, countries sharing borders in the region, including Vietnam, have established over 70 BLO Offices. Because BOL is located close to the border, each country's BLO office serves as a hub receiving information on the situation of drug-related crimes from neighboring border areas. BLO's office has 5-7 members representing law enforcement agencies including Police, Customs, Border Guard. Accordingly, they implement as a national focal point to contact, exchange information, periodically and unexpectedly meet between the police offices, customs offices, border guards stationed in the border areas of Vietnam and relevant agencies of Laos, Cambodia, China to serve the drug prevention and control on Vietnam border and other countries (UNODC, 2015). To act as a clue to receive and directly carry out the tasks of the project such as gathering, processing information and advising the Project Steering Committee, the Standing Office of Drug-related Crime Prevention and Fighting in the implementation of the work as scheduled. Up to now, Vietnam has deployed 14 BLO Offices on the border and inland border areas. Vietnam-China border covers four BLOs in Mong Cai (Quang Ninh), Thanh Thuy (Ha Giang), Lao Cai, and Lang Son; Vietnam-Lao borderline includes five BLOs At Cau Treo (Ha Tinh), Lao Bao (Quang Tri), Dien Bien (Dien Bien province), Moc Chau (Son La), Que Phong (Nghe An); and the borderline between Vietnam and Cambodia locates at five BLO offices in Moc Bai, Xa Mat (Tay Ninh), An Phu, Tinh Bien, Tan Chau (An Giang). According to the results of annual reports of BLOs since their establishment (2000) until now, Vietnam BLOs have cooperated with neighboring BLOs to discover, exchange information, coordinate with functional forces in investigating and arresting crossborder drug crimes with a total of more than 200 cases, 200 subjects, seizing many drugs, opium and addictive 
drug tubes, guns and bullets and many related assets and vehicles (UNODC, 2015, 2017).

\subsection{Response on the Sea Borderlines}

In the sea border area, the executive force of Vietnam has effectively coordinated with the LEAs of many countries and territories such as Australia, Hong Kong, Taiwan, Thailand and Philippines in prevention, struggling with drug crimes on sea routes, particularly in exchanging and sharing information; coordinating in investigation, discovery and arrest of drug crimes through sea routes; supporting, improving the capacity for detecting drugs in seaports. In which, as one of the positive members in the region, Vietnam has participated the Container Control Program (CCP), which has been launched by UNODC and World Customs Organization (WCO) since 2003 to assist governments in strengthening the capacity of law enforcement forces to further improve the efficiency of container control on the seaports, minimize the risk of transnational organized crimes taking advantage of container transportation by sea to trade drugs illegally. The CCP aims to support nations to establish inter-disciplinary Working Groups to control seaports with the participation of representatives of functional units of LEAs. This program is not only to support functional forces to access information from container database systems of the World Customs Organization (WCO) and share via a network of global organizations and enterprises but also supervise and investigate suspected shipments. Currently, there are more than 40 countries in the world participating in CCP. Since 2005, through CCP, with the aid of USD 31 million from Canada, France, United States, Germany, Italy, United Kingdom, European Union. Both UNODC and WCO have attempted to implement the joint cooperation initiative in order to assist national governments in establishing database, sharing information, raising awareness and strengthening capacity of law enforcement forces to improve the efficiency of container control on the seaports. So far, this program has contributed to participating countries to detect and seizing approximately 50 tons of cocaine, 50 tons of marijuana, 805 tons of precursors and many other illegal goods.

Also, Vietnam also contributed to the initiative for a safe Mekong River, which China and Thailand started this initiative in 2012. Within the project framework, 6 member countries of Mekong River sub-region (Thailand, China, Laos, Myanmar, Cambodia and Vietnam) appointed their representatives to work at the Safe Mekong River Control Center (SMCC) in order to establish a mechanism to exchange and quickly process the information related to lines of illegal production, trading and transportation of drugs. In Phase 1 of the project, SMCC was located in China. At present, the project is entering into its Phase 2, and SMCC is located in Chiang Mai province, Thailand. Major activities of the initiative include 1) setting up checkpoints for examination and prevention of drugs; 2) patrolling on Mekong River with the simultaneous participation of functional forces of all member countries; 3) patrolling on rivers and randomly checking suspected ships traveling within the territory of each state; and 4) enhancing and revising regulations on control of ports/wharfs on Mekong River of the countries, namely Guan Lei Wharf (China), Muang Mom Wharf (Laos), Wan Pong Wharf (Myanmar), Chiang Saen Wharf (Thailand).

Apart from the CCP and SMCC on above, Vietnam also involves directly in the ASEAN Seaport Interdiction Task Force (ASITF). It aims to coordinate in preventing drug trafficking in ASEAN through international seaport border gates as well as to enhance cooperation among ASEAN countries to preventing drug trading into or transiting ASEAN region. Furthermore, the program strengthens the cooperation network among drug prevention and fighting agencies under national seaport preventing units of ASEAN and counterpart countries. Additionally, LEAs of each member enhanced information sharing, intelligence, and coordination concerning illegal trading of addictive substances, psychotropic substances, and precursors among preventing units at the seaports of ASEAN member countries and counterpart countries where necessary. By doing this, the program contributed to coordinate in the cross-border investigation and also promote interdisciplinary cooperation with other agencies such as migration agency, customs, border security among ASEAN countries to prevent drug trafficking by air or by sea.

With the activities of some cooperation frameworks among countries and information received annually by LEAs of Vietnam, from 2010 until now, 1,801 items of information on drug crime have been obtained from their partners (MPS, 2018). There includes 730 news on the situation of drug crime related to border areas and inland border gates, 685 reports on the status of drug crime related to sea border areas. Based on the coordination in receiving information on drug crime, the ANCIP has coordinated with functional forces of the Customs, Border Guards and Marine Police to implement professional measures, organize fierce fights against drug crime in border areas, border gates and on the sea, and has investigated and discovered a total of 10,992 cases, arrested 17,808 people, accounting for $8.09 \%$ of total cases found in the whole country.

However, the international cooperation in the past time still has some shortcomings in terms of form, measures, and contents and has not been promoted on all routes and significant areas, thus the motto of active and remote prevention and fighting against drug crime has not been timely. In critical areas such as border gates, seaports, the drug prevention is still passive and lack of proactivity in coordinating, capturing the situation and movements of criminal drug activities in the region and neighboring countries to take appropriate fighting measures. 


\section{Main Issues to Focus and Improve the Effectiveness of International Cooperation to Fight Transnational Drug Trafficking}

In both the National Program and National Strategy to Control, Prevent and Combat Drug Issues towards 2020 and orientations on 2030, Vietnam considered that enhancing international and regional cooperation among the Southeast Asian and beyond is one of the most pillar approaches to ensure the valuable contributions to combat drug trafficking. Accordingly, all LEAs had to request to look for and keep contact with their partners, particularly with shared borderlines' countries with Vietnam. To maintain and develop multilateral cooperation and bilateral relationship in the prevention and to fight against drug crime in land and sea border areas, the ANCIP of Vietnam, as core role will actively coordinate with functional forces of the Customers, Border Guards and Marine Police, will focus on following tasks:

Firstly, regarding the legal framework, Vietnam should develop and complete a legal basis relating to international cooperation to prevent and combat transnational drug trafficking across the borderline shared neighbors. To do it, MPS through ANCIP and its specific bodies proposes the Government to early sign the bilateral agreements on extradition of crimes, on the transfer of sentenced persons to prison. These legal documents will permit more cooperative and collaborative implementations among LEAs countries to fight transnational crimes. Besides that, Vietnam also should discuss and exchange with their partners in the region to specialize and regulate legal basis for cooperation in the prevention and fight of transnational crimes, including drug-related crimes. It will allow LEAs to exchange special information on drug-related crimes between units in charge of each country's drug prevention and fighting to ensure the convenience, promptness, and confidentiality. Furthermore, it also creates mutually study and discuss new regulations simplifying "border crossing procedures" when required to investigate, seize and arrest drug-related crimes or being hunted.

Secondly, at the annual meeting of senior offices to combat narcotics trafficking, Vietnam should suggest ASEAN's member directly to build a preliminary summing-up, review and draw experiences in international cooperation in the fight against drug-related crimes cross the borderline, including on land and sea. By doing this, it helps both policy-makers and practitioners more objective assessments and valuable information to identify what should be prioritized and enhanced to investigate drug trafficking cases cross borders between countries and also expand their cooperation scopes. In particular, more pay attention to discussing and exchanging with police experts from other countries, more achieve the best models to cooperate in fighting illicit drugs.

Thirdly, to learn experiences more positive, LEAs should be requested their partners to preliminary sum-up international cooperation in drug prevention and fighting, depending on each countries' priorities, every quarter and/or six months per year. Based on these outcomes, we have had conditions to study, consider and evaluate the real situation and results of the implementation of international cooperation on drug prevention and fighting. Moreover, on that basis, guidelines, solutions, and measures to improve the efficiency of foreign aid in drug prevention and fight in general and global cooperation in drug prevention and fighting in the borderland and the sea have been recommended and proposed.

Fourthly, with respect of cooperation and collaboration on the sea to combat illicit flows of transnational narcotics, Vietnam and their partner at the GMS and ASEAN should more elaborated analyses and identifies their emergent trends of drug trafficking. In particular, all hotpot routes at the seaports should be considered and mapped on their visualization's documents which can share each LEAs for ordinating to arrest and investigate. However, to do it, all countries need to build a regulation on coordination between the people's police forces in the local borderlines' areas the sea. In which, some prioritized duties such as controlled delivery combined surveillance the goods transportation and circulation along these borderline's routes that should be approved to investigate complicated drug-related cases.

Fifthly, Vietnam also welcomes and appreciate their partners to enhance coordination in the exchange and processing of information on the routes of illegal drug trafficking related to each country on land and sea. More critical, LEAs will enhance to exchange and share trickery on purchase, sale, transportation, and concealment of drugs as well as experience of detection, prevention and fighting against drug-related crimes to take the initiative in preventing and managing drug-related crimes. To set up and complete the procedures of receiving and processing the information on drug-related crimes and working procedures relating to international cooperation of the forces in charge of fighting against drug-related crimes in border areas, border gates and on the sea.

Sixthly, training and fostering officials in international cooperation of all LEAs in Vietnam and their partners in the drug-related crime prevention and fighting that should implement and deploy as frequently and intensive as possible. For Vietnam, training programs in schools of the institutions need designed and introduce international treaties on crime prevention and fighting in general and drug-related crimes in particular. These curriculums will help educate and train more powerful motivation for officers during their contact and exchange their partners in investigation drug trafficking cases. Besides, police training should also introduce and analyze international criminal justice with arrest, extradition to criminals as well as international treaties on diplomatic and consular notices when conducting legal proceedings against foreigners who commit crimes in Vietnam. More spending time studying foreign language and training to improve the qualification of learners who shall be appointed to works of international 
cooperation is required as one of the most important 'soft skills' such as computer abilities, professional drive, and excellent communication's analysis. Also, it is necessary to develop a plan for training and retraining of responsible officers by opening short-term classes for training, updating information, sending them abroad by the theme. In this way, we have built a staff team making international cooperation in the fight against drug crimes to meet the high requirements.

\section{Inclusions}

International collaboration has contributed to improving the effectiveness of fighting against transnational drug trafficking in the regional and national context. In fact, the number of cases and arrests have increased and even expanded many international cases involving international affairs that require all LEAs in each country in the region need to improve the effectiveness of information exchange. Besides that, the Government should enhance in coordinate management and control precursor chemicals used for illegal production of narcotics. In the past years, through international cooperation in drug prevention and combat, Vietnam has learned and exchanged experiences on drug prevention and control from other countries, enlisted the support and assistance of staff training, detoxification on funds, equipment of international and regional support. Forecast of drug crimes in Vietnam and many countries in Southeast Asia will increase in the future. The fight against drug prevention in Vietnam and its shared border countries in the region will be difficult and hard. However, the reality shows that the cooperation in drug prevention and combat between Vietnam and other countries is still not commensurate with the needs of each country. In the next time, based on the agreement and commitments with states, the Vietnamese authorities and the parties need to strengthen further and expand cooperation with other countries to meet with the requirements of the new situation. Besides that, other countries shared borderland in the region such as Vietnam, Laos, Cambodia, Thailand and Myanmar should enhance to cooperate and collaborate to joint further research in organizational structure and modus operandi of drug trafficking groups and networks. By doing this, these findings can assist LEAs more understanding about the nature of transnational drug trafficking and also more effective cooperation in prevent and combat in the future.

\section{Reference}

ASEAN-NARCO. (2017). ASEAN Drug Monitoring Report 2016. Retrieved from Bangkok, Thailand: ASEAN-NARCO. (2018). ASEAN Drug Monitoring Report 2017. Retrieved from Bangkok, Thailand:

Hai, Thanh Luong. (2017). Drug Trafficking Trends and Its Responses: A Case Study of Vietnam. In Emilio Viano (Ed.), Cybercrime, Organized Crime, and Societal Responses: International Approaches (pp. 201-219). Cham, Switzerland: Springer.

Hai, Thanh Luong. (2019a). Transnational Drug Trafficking across the Vietnam-Laos Border. Cham, Switzerland: Palgrave MacMillan.

Hai, Thanh Luong. (2019b). Vietnam and the Mekong's Synthetic Drug Epidemic. The Diplomat.

Hiep, Hong Le. (2014). Living Next to the Giant: The Political Economy of Vietnam's Relations with China under Doi Moi. (PhD), The University of New South Wales, Canberra.

Hiep, Hong Le. (2017). Living Next to the Giant: The Political Economy of Vietnam's Relations with China under Doi Moi. Singapore: ISEAS-Yosof Ishak Institute.

IDPC. (2018). Taking Stock: A Decade of Drug Policy. Retrieved from New York:

IDPC. (2019). The 'Vienna Consensus' Stifles Progress on UN Drug Policy [Press release]

Ladegaard, Isak. (2019). Crime Displacement in Digital Drug Markets. International Journal of Drug Policy, 63(1), 113-121.

Moyle, Leah, Childs, Andrew, Coomber, Ross, \& Barratt, Monica. (2019). \#Drugsforsale: An Exploration of the Use of Social Media and Encrypted Messaging Apps to Supply and Access Drugs. International Journal of Drug Policy, 63(1), 101-110.

MPS. (2017). Annual Report for Drug Situation in Vietnam. Retrieved from Hanoi, Vietnam

MPS. (2018). Annual Report for Drug Situation in Vietnam. Retrieved from Hanoi, Vietnam [Vietnamese language]:

Tasch, Barbara. (2015). The Dark Net Might be Changing Drug Smuggling Routes. Briefing. https://www.businessinsider.com.au/the-dark-net-might-be-changing-drug-smuggling-routes-2015$6 ? \mathrm{r}=\mathrm{US} \& \mathrm{IR}=\mathrm{T}$

Thang, Quoc. (2019). Drug Cartels Don Garb of Normal Business in HCMC. 21 April. Retrieved from https://e.vnexpress.net/news/news/drug-cartels-don-garb-of-normal-business-in-hcmc-3912646.html

Thayer, Carlyle. (2010 ). Political Legitimacy in Vietnam: Challenge and Response. Politics \& Policy, 38(3), 423444.

Thayer, Carlyle. (2011). The Tyranny of Geography: Vietnamese Strategies to Constrain China in the South China Sea. Contemporary Southeast Asia: A Journal of International and Strategic Affairs, 33(3), 348-369.

Thayer, Carlyle. (2012). Vietnam's Security Outlook. In The National Institute for Defense Studies (Ed.), Security 
Outlook of the Asia Pacific Countries and Its Implications for the Defense Sector (pp. 69-89). Tokyo, Japan: The National Institute for Defense Studies.

Turner, Sarah, Bonnin, Christine, \& Michaud, Jean. (2015). Frontier Livelihoods: Hmong in the Sino-Vietnamese Borderlands. Seattle: University of Washington Press.

UNODC. (2013). Border Control in the Greater Mekong Sub-region: Baseline, challenges and opportunities to build effective law enforcement response to organized crime along land borders Retrieved from Bangkok, Thailand:

UNODC. (2015). Partnership, Cooperation and Action in the Greater Mekong Sub-region: The Memorandum of Understanding (MOU) on Drug Control. Retrieved from Bangkok, Thailand:

UNODC. (2017). Partnership, Cooperation and Action in the Greater Mekong Sub-region: The Memorandum of Understanding (MOU) on Drug Control. Retrieved from Bangkok, Thailand:

UNODC. (2018). Understanding the Synthetic Drug Market: the NPS Factor Retrieved from New York:

UNODC. (2019). Synthetic Drugs in East and South-East Asia: Trends and Patterns of Amphetamine-Type Stimulants and New Psychoactive Substances. Retrieved from Vienne, Austria:

VNS. (2018, 3 July). Drug Trafficking Kingpins Killed in Son La Police Raid. Vietnam News. Retrieved from https://vietnamnews.vn/society/450958/drug-trafficking-kingpins-killed-in-son-la-policeraid.html\#ztkV4chYisjeSOdD.97

VTV (Writer) \& Trung tam Phim Tai lieu va Phong su (Director). (2018). Long Luong, Van Ho, Son La - 'Chao lua’ ve Ma Tuy tai Tay Bac. In Hoang Nguyen Lam (Producer), Lan theo Dau vet. Hanoi, Vietnam: Vietnam Television (VTV) [trans: Long Luong, Van Ho, Son La - 'Central Location' on Drugs at North-West, 2018].

Vuving, Alexander. (2010). Vietnamese Perspectives on Transnational Security Challenges. In David Fouse (Ed.), Issues for engagement: Asian Perspectives on transnational security challenges (pp. 167-179). Hawaii: the Asia-Pacific Centrer for Security Studies.

Wilson, Jeffrey (Ed.) (2018). Vietnam in the Indo-Pacific: Challenges and Opportunities in a New Regional Landscape. Perth, South Australia: Perth USAsia Centre. 